\title{
Demirci/Manisa Ekolojisinde Organik Badem Yetiştiriciliğinin Uygulanabilirliği
}

\author{
Applicability of Organic Almond Growing in Demirci/Manisa District
}

\section{Nihal ACARSOY BİLGİN}

Ege Üniversitesi Ziraat Fakültesi Bahçe

Bitkileri Bölümü Bornova / İzmir

0000-0002-5018-6347

Sorumlu Yazar: nihalacarsoy@yahoo.com

Gönderilme Tarihi : 28 Nisan 2020

Kabul Tarihi

\section{ÖZET}

Badem, ülkemizde yetiştiriciliği yapılan en eski meyve türlerinden birisidir. Geç çiçeklenen çeşitlerin geliştirilmesi nedeniyle son dönemlerde bu çeşitlerle tesis edilen bahçe sayısı artış göstermektedir. Diğer yandan, organik yetiştiricilik açısından da dikkat çeken bir türdür. Meyvecilikte çeşitlerin değişik ekolojilere adaptasyonunun tespiti ve yaygınlaştırılması önem taşımaktadır. $\mathrm{Bu}$ bağlamda, Manisa ili Demirci ilçesinde yürütülen çalışmada, organik olarak yetiştiriciliği yapılan Ferragnes ve Ferraduel badem çeşitlerin bazı meyve özellikleri ve verim durumlarının tespiti amaçlanmıştır. Buna göre, iklim koşulları ve ağacın gelişmesine bağlı olarak, denemenin ilk yllında ince kabuk ve daha az çift iç oran, ikinci yılda ise daha yüksek verim saptanmıştır. Çeşit x yıl interaksiyonun önemli olması nedeniyle, Ferragnes çeşidinde 2018 yılında ve Ferraduel çeşidinde 2019 yılında iç randımanı yüksek (\%30.23 ve \%26.46), ince kabuklu (3.07 $\mathrm{mm}$ ve 3.73 $\mathrm{mm})$ ve çift iç oranı az (\%0.00 ve \%16.67) olan meyveler belirlenmiştir. Benzer şekilde, kabuklu meyve ağırlığı da çeşitlere ve y1llara göre değişim göstermiştir. En yüksek değer, Ferragnes çeşidinde 2019 yllında (5.20 g) buna 
karş11ık, Ferraduel çeşidinde ise 2018 y1lında $(5.71 \mathrm{~g})$ görülmüştür. Verim çeşitlere göre değişmezken yıllara göre beklenen bir farklılık görülmüştür. Ayrıca incelenen özellikler arasında korelasyon ilişkisi de değerlendirilmiştir. $\mathrm{Bu}$ bulgular doğrultusunda çeşitlerin yöreye uyum sağladığ 1 ve organik olarak yetiştirilebileceği sonucuna ulaşılmıştır.

Anahtar kelimeler: Amygdalus communis, organik yetiştiricilik, adaptasyon, meyve, verim

\section{Abstract}

Almond is one of the oldest fruit species grown in our country. Due to the development of late flowering varieties, the number of orchards established with these varieties has recently increased. On the other hand, it is a remarkable species in terms of organic agriculture. In fruit growing, it is important to determine and spread the adaptation of varieties to different ecologies. In this context, in the study carried out in Demirci/Manisa district, it was aimed to determine some fruit characteristics and yield of Ferragnes and Ferraduel almond varieties organically grown. Accordingly, depending on the climatic conditions and the growth of the tree, in the first year of the experiment, thin shell and less double kernel ratio were determined, while the yield was higher in the second year. Due to the fact that variety $\mathrm{x}$ year interaction was important, in Ferragnes variety in 2018 and Ferraduel variety in 2019, its kernel ratio is high (30.23\% and $26.46 \%)$, thin shell $(3.07 \mathrm{~mm}$ and $3.73 \mathrm{~mm})$ and double kernel ratio $(0.00 \%$ and $16.67 \%$ ) were identified. Similarly, fruit weight varied by variety and years. The highest value was observed in the Ferragnes variety in 2019 $(5.20 \mathrm{~g})$, whereas in the Ferraduel variety in 2018 (5.71 g). The yield did not change according to the varieties, an expected difference was observed for the years. In addition, the correlation relationship among the investigated features was evaluated. According to these findings, it was concluded that the varieties can adapt to the region and can be grown organically.

Keywords: Amygdalus communis, organic growing, adaptation, fruit, yield

\section{Giriş}

Kurak iklim koşullarının tipik bitkisi olan badem (Amygdalus communis L.), ülkemizin birçok bölgesinde yetiştirilen önemli sert kabuklu bir meyve türüdür (Dokuzoğuz ve Gülcan, 1973; Küden ve ark., 2014). Çerez, şekerleme, çikolata, pasta, kozmetik ve ilaç endüstrisi olmak üzere farklı tüketim alanları bulunmakta olup ekonomik açıdan değer taşımaktadır. Günümüzde, besin değerinin yüksek olması nedeniyle diyet programlarının önemli bir yapı taşını oluşturmaktadır (Şimsek, 2016). Kuru meyvelerin muhafaza kolaylı̆̆ diğer bir avantajıdır. Ayrıca erken verime yatması, yetiştiriciliğinin yaygınlaşmasına yol açmaktadır. Bu bağlamda, söz konusu meyve türüne ilginin artış gösterdiği dikkat çekmektedir. Meyve türlerinde verim ve kalite; genetik yap1, ekolojik koşullar ve kültürel uygulamalara bağlı olarak değişim göstermektedir. Çeşitlerin ekolojik koşullara adaptasyonu bakımından farklılıklar bulunmaktadır. Ancak bölgeye uyum sağlayan çeşitlerle optimum miktar ve kaliteye ulaşılabilmektedir. Meyveciliğin zor ve pahalı bir yatırım olması dolayısıyla çeşitlerin 
adaptasyon denemelerinin mutlaka yapılması gerekmektedir (Atl1 ve ark., 2008; Aslan, 2015; Yıldız ve Erol Perdahc1, 2019). Diğer yandan, pazar talepleri doğrultusunda farklı yetiştiricilik sistemleri gündeme gelmektedir. Üretim süresince yoğun sentetik gübre ve ilaç kullanımı çevre ve insan sağlığını olumsuz yönde etkilemektedir. Doğal dengenin öneminin vurgulandığı son dönemlerde, mevcut sorunların çözümüne alternatif olabilecek ekolojik sisteme zarar vermeyen ve üretimde sürdürebilirliği esas alan çevreye duyarlı üretim teknikleri konusundaki uygulamalar önem kazanmıştır (Aksoy, 2001). Söz konusu aktiviteler 1980'li yıllarda başlamış olup günümüze kadar farklı sistemler gelişmiştir. Geleneksel üretimin yanı sıra organik yetiştiricilik yaygınlaşmış olup bu ürünlerin pazar değeri de artış göstermektedir (Gök, 2008; Atalay, 2016). Özellikle kurutulmuş meyveler ve badem dikkat çekmektedir (Ersun ve Arslan, 2011). Bu bağlamda, Badem ve findık gibi meyve türlerinde organik ve konvansiyonel uygulamaların meyve özellikleri üzerine etkilerinin karşılaştırıldığı araştırmalar bulunmaktadır (Özyazıcı ve ark., 2010; Turan ve ark., 2010; Karaat, 2019).

Badem üretimi açısından önem taşıyan Ege Bölgesi'nde yer alan Manisa ili Demirci ilçesinde son zamanlarda kapama bahçelerin tesis edildiği gözlenmektedir. Bu tür için önem taşıyan geç çiçeklenme özelliği nedeniyle önemli avantaja sahip olan Ferragnes ve Ferraduel çeşitleri tercih edilmektedir. İlçede yapılan anket çalışmasında, bu lokasyonun geniş ürün çeşitliliğine sahip olmasının, organik tarım açısından öne çıkan güçlü yönünü oluşturduğu vurgulanmaktadır (Yercan ve Özden, 2015). Bu çalışmada,
Demirci ilçesinde organik yetiştiriciliği yapılan her iki badem çeşidinin, verim ve bazı meyve özellikleri belirlenerek performansının tespiti amaçlanmıştır.

\section{Materyal ve Yöntem}

Demirci/Manisa'da organik olarak yetiştiriciliği yapılan Ferragnes ve Ferraduel badem çeşitleri çalışma materyalini oluşturmuştur. Çöğür anacı üzerine aşılı fidanlarla 2013 yılında tesis edilen (5 x $5 \mathrm{~m}$ ) bahçede, bilinçsiz ve aşırı gübre ve pestisit kullanımının insan sağlığı ile çevre üzerine zararlarını bertaraf eden organik tarım sistemi ile kontrollü ve sertifikalı tarımsal üretim yapılmaktadır. $\mathrm{Bu}$ bahçede 2018 ve 2019 yıllarında yürütülen çalışmada, ağaçlara; çiftlik gübresi, yeşil gübre ve analiz sonuçlarına göre uygun dozlarda organik tarıma ruhsatlı yaprak gübresi verilmiştir. Bahçede düzenli kültürel uygulamalar ve sulama yapılmıştır. Deneme alanının bulunduğu lokasyona ait aylık maksimum ve minimum sicaklık değerleri Çizelge 1'de yer almaktadır.

Ağustos - Eylül döneminde hasat edilen meyveler, kabuklarından ayrılarak gölgede kurulmuştur. Meyve analizleri Ege Üniversitesi Ziraat Fakültesi Bahçe Bitkileri Bölümü'nde yapılmıştır. Ortalama meyve ağırlığı ve iç ağırlığı için örnekler $0.01 \mathrm{~g}$ duyarlı elektronik terazide tartılmıştır. Meyve ve iç ağırlığı belirlenen örneklerin iç randımanı \% olarak belirlenmiştir. Kabuklu ve iç bademlerin eni (genişlik, yanak çap1), boyu (uzunluk), yüksekliği (kalınlık, sutur çap1) ve kabuk kalınlığı mm cinsinden 0.01 mm'ye duyarlı dijital kumpas yardımıyla ölçülmüştür. İç bademin rengi Minolta kolorimetresi (CR-400, Minolta Co, Japonya) ile CIE $L^{*}, a^{*}, b^{*}$ cinsinden okunmuştur. Elde 
edilen $\mathrm{a}^{*}$ ve $\mathrm{b}^{*}$ değerlerinden kroma $\left(\mathrm{C}^{*}=\left[\mathrm{a}^{*} 2\right.\right.$ $\left.\left.+b^{* 2}\right] 1 / 2\right)$, ve hue açısı $\left(h^{\circ}=\tan -1\left[b^{*} / a^{*}\right]\right)$ değeri hesaplanmıştır (McGuire, 1992). Çift badem oran $1 \%$, verim ise $\mathrm{kg}$ ağaç ${ }^{-1}$ olarak belirlenmiştir.

İki faktörlü tesadüf blokları deneme desenine göre, 3 tekerrürlü olarak planlanan çalışmadan her tekerrürde 30 meyve örneği değerlendirilmiştir. Elde edilen veriler TARIST istatistik paket programı kullanılarak, varyans analizine tabi tutulmuştur (Açıkgöz ve ark., 1994). Ortalamalar arasındaki farklılıklar LSD testi ile ortaya konmuştur. değişim, iklim koşulları ve ağacın gelişmesine bağl1 olarak gerçekleşen doğal bir durumdur. Benzer şekilde, ortalama kabuk kalınlığı çeşitlere göre farkl1lık göstermiş olup bu değer Ferraduel ve Ferragnes çeşitlerinde sırasıyla $3.84 \mathrm{~mm}$ ve $3.47 \mathrm{~mm}$ olarak saptanmıştır.

Kabuklu meyve ağırlığı, kabuk kalınlığı, iç randımanı ve çift iç oranına ilişkin yapılan değerlendirmede, çeşit $\mathrm{x}$ y1l interaksiyonu istatistiksel açıdan anlamlı bulunmuştur. Kabuklu meyve ağırlığı, denemenin ilk ve ikinci yılında, Ferragnes çeşidinde 4.31 $5.20 \mathrm{~g}$; Ferraduel çeşidinde ise $5.71-4.90 \mathrm{~g}$

Çizelge 1. Aylık ortalama sıcaklık değerleri $\left({ }^{\circ} \mathrm{C}\right)$

\begin{tabular}{|c|c|c|c|c|c|c|c|c|c|c|c|c|c|}
\hline \multicolumn{2}{|c|}{} & Ocak & Şubat & Mart & Nisan & Mayıs & Haziran & Temmuz & Ağustos & Eylül & Ekim & Kasım & Aralık \\
\hline \multirow{2}{*}{2018} & Max & 9.3 & 11.6 & 15.0 & 23.1 & 24.7 & 27.5 & 30.3 & 31.4 & 27.2 & 22.1 & 16.1 & 8.3 \\
\cline { 2 - 13 } & Min & 2.9 & 5.2 & 6.9 & 12.4 & 14.3 & 16.7 & 19.2 & 20.1 & 16.8 & 12.1 & 8.6 & 2.0 \\
\hline \multirow{2}{*}{2019} & Max & 6.7 & 11.0 & 14.7 & 16.5 & 23.2 & 27.6 & 29.8 & 32.1 & 28.1 & 24.2 & 18.8 & 10.7 \\
\cline { 2 - 13 }$y$ & Min & 1.5 & 3.0 & 4.9 & 7.7 & 13.5 & 17.4 & 18.9 & 20.6 & 16.4 & 14.0 & 10.8 & 4.7 \\
\hline
\end{tabular}

\section{Bulgular ve Tartışma}

Organik yöntemle yetiştirilen Ferragnes ve Ferraduel badem çeşitlerinin bazı meyve özellikleri ve verim Çizelge 2'de verilmiştir. Kabuk kalınlığı, çift iç oranı ve verim değerleri yıllara bağlı olarak istatistiksel farkl11 1k göstermiştir. Buna göre, her çeşidin ortalaması dikkate alındığında, denemenin ilk yılında ince kabuk ve daha az çift iç oranı belirlenirken, ikinci yılda ise daha yüksek verim elde edilmiştir. $\mathrm{Bu}$ aralığında değişim göstermiştir. Böylece, en yüksek kabuklu meyve ağırlığı, Ferragnes çeşidinde ikinci, Ferraduel çeşidinde ise birinci yılda ölçülmüsstür. Diğer taraftan, iç randımanı yüksek, ince kabuklu ve çift iç oranı az olan meyveler Ferragnes çeşidinde 2018, Ferraduel çeşidinde ise 2019 yılında elde edilmiştir. Çeşitler arasında istatistiksel olarak farkl1lık görülmemekle birlikte, Ferraduel çeşidinde (5.53 $\mathrm{kg}$ ağaç-1) nispeten verimin daha yüksek olduğu saptanmıştır. İkinci yılda verim değerleri ilk yıla kıyasla daha yüksek bulunmuştur. Bu durum, 
Çizelge 2. Meyve özellikleri ve verim

\begin{tabular}{|c|c|c|c|c|c|c|c|}
\hline & & $\begin{array}{l}\text { Kabuklu } \\
\text { meyve } \\
\text { ağırlığ } 1(\mathrm{~g})\end{array}$ & $\begin{array}{c}\text { İç badem } \\
\text { ağırlığ1 (g) }\end{array}$ & $\begin{array}{c}\text { Kabuk } \\
\text { kalınlığ } 1 \\
(\mathrm{~mm})\end{array}$ & $\begin{array}{c}\text { İç randımanı } \\
(\%)\end{array}$ & $\begin{array}{l}\text { Çift iç oranı } \\
\qquad(\%)\end{array}$ & $\begin{array}{c}\text { Verim } \\
\text { (kg ağaç-1) }\end{array}$ \\
\hline \multirow{3}{*}{ Ferragnes } & 2018 & 4.31 & 1.30 & 3.07 & 30.23 & 0.00 & 4.83 \\
\hline & 2019 & 5.20 & 1.19 & 3.87 & 23.25 & 13.33 & 5.77 \\
\hline & Ortalama & 4.75 & 1.25 & $3.47 \mathrm{~b}$ & 26.74 & 6.67 & 5.30 \\
\hline \multirow{3}{*}{ Ferraduel } & 2018 & 5.71 & 1.33 & 3.94 & 23.28 & 33.33 & 4.97 \\
\hline & 2019 & 4.90 & 1.29 & 3.73 & 26.46 & 16.67 & 6.10 \\
\hline & Ortalama & 5.31 & 1.31 & $3.84 \mathrm{a}$ & 24.87 & 25,00 & 5.53 \\
\hline \multicolumn{2}{|l|}{ LSD } & öd & öd & 0.25 & 5.944 & 7.357 & 0.94 \\
\hline \multicolumn{2}{|l|}{ Çeşit } & öd & öd & $*$ & öd & öd & öd \\
\hline \multicolumn{2}{|l|}{ Y1l } & öd & öd & $*$ & öd & $* *$ & $* *$ \\
\hline \multicolumn{2}{|l|}{ Çeşit*Y1l } & $*$ & öd & $* *$ & $*$ & $* *$ & öd \\
\hline
\end{tabular}

ağacın fizyolojik olgunluğu ve gelişiminin doğal bir sonucu olarak ortaya çıkmaktadır. Nitekim, meyve özellikleri ve verim genetik, çevresel koşullar, kültürel uygulamaların interaksiyonu ve bitki metabolizmasına etkisinin bir sonucu olarak ortaya çıkabilmektedir. Deneme alanının sicaklık değerlerinin badem çeşitlerinin soğuk ihtiyacının karşılanması ve çiçeklenme açısından sorun oluşturmadığ1 görülmektedir.
Denemede, kabuklu meyve eni çeşitler arasında buna karşılık, iç badem boyu yıllar arasında istatistiksel düzeyde önemli farklılık göstermiştir (Çizelge 3). Kabuklu bademin eni, Ferragnes çeşidinde $22.78 \mathrm{~mm}$ iken Ferraduel çeşidinde $23.82 \mathrm{~mm}$ olarak ölçülmüştür. Ayrıca her iki badem çeşidinin kabuklu meyve boyutları yıllara göre değişim göstermiştir. Çeşitler iç badem özellikleri bakımından değerlendirildiğinde,

Çizelge 3. Kabuklu ve iç badem boyutları (mm)

\begin{tabular}{|c|c|c|c|c|c|c|c|}
\hline & & $\begin{array}{c}\text { Kabuklu } \\
\text { en }\end{array}$ & $\begin{array}{c}\text { Kabuklu } \\
\text { boy }\end{array}$ & $\begin{array}{c}\text { Kabuklu } \\
\text { yükseklik }\end{array}$ & $\begin{array}{l}\text { İç badem } \\
\text { en }\end{array}$ & $\begin{array}{l}\text { İç badem } \\
\text { boy }\end{array}$ & $\begin{array}{l}\text { İç badem } \\
\text { yükseklik }\end{array}$ \\
\hline \multirow{3}{*}{ Ferragnes } & 2018 & 21.76 & 35.04 & 15.93 & 13.79 & 27.59 & 7.52 \\
\hline & 2019 & 23.79 & 35.54 & 16.91 & 14.74 & 24.07 & 7.30 \\
\hline & Ortalama & $22.78 \mathrm{~b}$ & 35.29 & 16.42 & 14.27 & 25.83 & 7.41 \\
\hline \multirow{3}{*}{ Ferraduel } & 2018 & 24.78 & 37.12 & 17.53 & 14.31 & 26.59 & 7.44 \\
\hline & 2019 & 22.85 & 35.02 & 16.38 & 14.31 & 24.47 & 7.77 \\
\hline & Ortalama & $23.82 \mathrm{a}$ & 36.07 & 16.96 & 14.31 & 25.53 & 7.61 \\
\hline \multicolumn{2}{|l|}{ LSD } & 0.75 & öd & öd & öd & 1.08 & öd \\
\hline \multicolumn{2}{|l|}{ Çeşit } & $*$ & öd & öd & öd & öd & öd \\
\hline \multicolumn{2}{|l|}{ Yil } & öd & öd & öd & öd & $* *$ & öd \\
\hline \multicolumn{2}{|l|}{ Cesit*Y1l } & $* *$ & * & * & öd & öd & $*$ \\
\hline
\end{tabular}


ilk yılda, iç badem boyunun daha uzun olduğu istatistiksel olarak belirlenmiştir. Kabuklu bademe benzer şekilde, iç badem yüksekliği bakımından çeşit x yıl interaksiyonu önemli bulunmuştur.

Ferragnes ve Ferraduel çeşitlerinin Uşak ekolojik koşullarına adaptasyonunun belirlendiği çalışmada, 4 yaşlı ağaçlarda kabuklu meyve ağırlığı sırasıyla $4.15 \mathrm{~g}$ ve $4.02 \mathrm{~g}$ olarak bulunurken ortalama verim $1.1-1.7 \mathrm{~kg}$ ağaç-1 olarak tespit edilmiştir (Yıldız ve Erol Perdahc1, 2019).

Şanlıurfa koşullarında konvansiyonel yetiştiriciliği yapılan Ferragnes çeşidinde ortalama meyve boyu kalınlığı, eni, kabuklu ağırlığı, iç ağırlığı ve randımanı sırasıyla 32.56 mm, $22.49 \mathrm{~mm}, 15.25 \mathrm{~mm}, 3.29 \mathrm{~g}, 1.16 \mathrm{~g}$ ve \%31.11 belirlenirken, Ferraduel çeşidinde ise $33.43 \mathrm{~mm}, 23.14 \mathrm{~mm}, 16.01 \mathrm{~mm}, 3.73 \mathrm{~g}, 1.22$ g ve \%31.01 olduğu ifade edilmektedir. Ayrıca her iki çeşitte de ikiz meyve oranının az olduğu bildirilmiştir (Parlakçı, 2008). Benzer şekilde, sözkonusu bu çalışmada da kabuklu meyve eninin çeşitlere göre değiştiği ve bu değerin Ferraduel çeşidinde daha yüksek olduğu saptanmıştır. İç randıman oranının ise yaklaşık \%26 ile nispeten daha düşük olduğu belirlenmiştir.

Aydın ekolojisinde Gülsoy ve Balta (2014), tarafından yapılan diğer bir çalışmada ise, Ferragnes çeşidinin kabuklu meyve ağırlığının $3.43 \mathrm{~g}$, meyve genişliğinin $22.09 \mathrm{~mm}$, meyve boyunun $33.36 \mathrm{~mm}$, iç ağırlığının $1.12 \mathrm{~g}$, iç meyve kalınlığının $6.84 \mathrm{~mm}$, iç meyve genişliğinin $13.47 \mathrm{~mm}$, iç meyve boyunun $25.51 \mathrm{~mm}$ olduğunu bildirilmektedir. Demirci ekolojisinde organik yetiştiriciliği yapılan bu çeşitten elde edilen söz konusu bulguların daha yüksek olduğu belirlenmiştir. Ayrıca GAP Bölgesi’nde sulu koşullarda yapılan yetiştiricilikte, söz konusu çeşitler, yerli ve yabancı birçok çeşide göre yüksek performans sergilemiştir (Atlı ve ark., 2008).

Karaat (2019), tarafindan Adiyaman ekolojisinde organik ve konvansiyonel yöntemle yetiştirilen bu çeşitlerin, kabuklu ve iç badem boyutlarının çeşitlere göre önemli bir değişim gösterdiği bununla beraber, konvansiyonel ve organik örnekler arasında farklılık bulunmadığ 1 vurgulanmıştır. Meyve ağırlığı için, Ferraduel çeşidinde, organik (4.9 g) ve konvansiyonel (4.6 g) yetiştiricilik sisteminde önemli farklılık belirlenirken, Demirci ekolojisinde yürütülen bu çalışmada organik yetiştiricilikte söz konusu değerin (5.31 g) çok daha yüksek olduğu saptanmıştır.

Sert kabuklu meyveler grubuna dahil bir tür olan fındıkta, organik yetiştiricilikte meyve ve iç ağırlığı, kabuk kalınlığı ve verim üzerine yetiştirme şeklinin etkisinin önemsiz olduğu bildirilmektedir (Özyazıcı ve ark., 2010; Turan ve ark., 2010). Meyve özelliklerin çeşitlere göre değişimi, genetik yapıdan kaynaklanabildiği gibi yıllara bağlı olarak da ortaya çıkabilmektedir. Aynı çeşitlerle değişik ekolojik koşullarda yürütülen diğer çalışmalarda, özelliklerin değişimin; lokasyon, ağaç yaşı, ürün miktarı, çevresel koşullar ve kültürel uygulamaların etkisinden kaynaklandığ1 vurgulanmaktadır (Akçay ve Tosun, 2005; Oğuz ve ark., 2011). Meyve renk değerlerinin çeşit ve yıllara göre değişimi önem taşımamaktadır (Çizelge 4). Ferraduel çeşidinde $b^{*}$ değerinin (39.35) diğer çeşide göre (38.44) daha yüksek olması bu çeşidin kısmen açık sarı renkte olduğunu 
Çizelge 4. Meyve renk parametreleri

\begin{tabular}{|l|l|c|c|c|c|c|}
\cline { 3 - 6 } \multicolumn{2}{c|}{} & $\mathrm{L}^{*}$ & $\mathrm{a}^{*}$ & $\mathrm{~b}^{*}$ & $\mathrm{C}^{*}$ & $\mathrm{~h}^{0}$ \\
\hline \multirow{3}{*}{ Ferragnes } & 2018 & 47.10 & 17.90 & 38.88 & 42.80 & 65.27 \\
\cline { 2 - 7 } & 2019 & 45.84 & 18.57 & 38.00 & 43.08 & 65.30 \\
\cline { 2 - 7 } & Ortalama & 46.47 & 18.24 & 38.44 & 42.94 & 65.29 \\
\hline \multirow{3}{*}{ Ferraduel } & 2018 & 47.42 & 17.98 & 39.15 & 42.30 & 63.94 \\
\cline { 2 - 7 } & 2019 & 48.49 & 18.05 & 39.56 & 43.48 & 65.45 \\
\cline { 2 - 7 } & Ortalama & 47.95 & 18.01 & 39.35 & 42.89 & 64.69 \\
\hline LSD & öd & öd & öd & öd & öd \\
\hline Çeşit & öd & öd & öd & öd & öd \\
\hline Y1l & öd & öd & öd & öd & öd \\
\hline Çeşit*Y11 & öd & öd & öd & öd & öd \\
\hline
\end{tabular}

öd: önemli değil.

göstermektedir. Kroma değerinin ikinci yılda daha doygun renge ulaşmıştır. nispeten daha yüksek olması nedeniyle çeşitler

Çizelge 5. Özellikler arasındaki Pearson korelasyon katsayıları

\begin{tabular}{|c|c|c|c|c|c|c|c|c|c|c|c|c|c|c|c|c|}
\hline & IA & $\mathbf{R}$ & ME & MB & MY & IE & iB & IY & KK & ML & Ma & Mb & MK & MH & çi & v \\
\hline MA & -0.21 & $-0,92^{* *}$ & $0,84^{\prime \prime}$ & $0,70^{\circ}$ & $0,85^{*}$ & 0,50 & $-0,31$ & $-0,36$ & $0,59^{*}$ & $-0,15$ & 0,34 & $-0,11$ & $-0,05$ & $-0,36$ & 0,47 & 0,15 \\
\hline İA & & 0,56 & $-0,16$ & 0,05 & $-0,12$ & $-0,60^{*}$ & 0,46 & $0,58^{*}$ & $-0,149$ & $-0,04$ & $-0,81^{\text {** }}$ & $-0,18$ & $-0,30$ & 0,41 & $-0,66^{*}$ & $-0,22$ \\
\hline $\mathbf{R}$ & & & $-0,77^{\star \star}$ & $-0,552$ & $-0,76^{* *}$ & $-0,65^{*}$ & 0,48 & 0,49 & $-0,59^{*}$ & 0,08 & $-0,61^{*}$ & $-0,01$ & $-0,10$ & 0,44 & $-0,67^{*}$ & $-0,24$ \\
\hline ME & & & & $0,87^{* *}$ & $0,74^{\star \star}$ & 0,45 & $-0,23$ & $-0,47$ & $0,66^{*}$ & $-0,07$ & 0,14 & 0,02 & 0,04 & $-0,10$ & 0,53 & $-0,04$ \\
\hline MB & & & & & $0,61^{\star}$ & 0,19 & 0,20 & $-0,51$ & 0,36 & $-0,13$ & $-0,07$ & $-0,02$ & $-0,03$ & 0,00 & 0,18 & $-0,38$ \\
\hline MY & & & & & & 0,33 & $-0,20$ & $-0,18$ & 0,51 & $-0,08$ & 0,22 & $-0,07$ & $-0,03$ & $-0,24$ & 0,41 & 0,10 \\
\hline İE & & & & & & & $-0,66^{*}$ & $-0,38$ & $0,66^{*}$ & $-0,12$ & 0,53 & $-0,07$ & 0,01 & $-0,46$ & $0,78^{* *}$ & 0,45 \\
\hline їB & & & & & & & & $-0,08$ & $-0,57^{*}$ & 0,08 & $-0,45$ & 0,11 & 0,04 & 0,43 & $-0,80^{* *}$ & $-0,83^{* *}$ \\
\hline iY & & & & & & & & & $-0,10$ & 0,23 & $-0,44$ & 0,06 & $-0,01$ & 0,38 & $-0,39$ & 0,41 \\
\hline KK & & & & & & & & & & 0,09 & 0,28 & 0,15 & 0,18 & $-0,07$ & $0,65^{*}$ & 0,29 \\
\hline ML & & & & & & & & & & & 0,13 & $0,93^{* *}$ & $0,90^{* *}$ & $0,78^{\star *}$ & $-0,25$ & $-0,15$ \\
\hline Ma & & & & & & & & & & & & 0,28 & 0,42 & $-0,45$ & 0,50 & 0,10 \\
\hline Mb & & & & & & & & & & & & & $0,98^{* *}$ & $0,72^{\star * *}$ & $-0,17$ & $-0,28$ \\
\hline MK & & & & & & & & & & & & & & $0,61^{*}$ & $-0,08$ & $-0,25$ \\
\hline МH & & & & & & & & & & & & & & & $-0,53$ & $-0,33$ \\
\hline Çí & & & & & & & & & & & & & & & & 0,52 \\
\hline
\end{tabular}

Kısaltmalar: Meyve ağırlığı: MA, İç ağırlığı: İA, Randıman: R, Meyve Eni: ME, Meyve boyu: MB, Meyve Yüksekliği: MY, İç Eni: İE, İç boyu: İB, İç Yüksekliği: İY, Kabuk kalınlığg: KK, Meyve L değeri: ML, Meyve a değeri: Ma, Meyve b değeri: Mb, Meyve kroma değeri: MK, Meyve Hue değeri: MH, Çift iç: Çİ, Verim: V 
İncelenen meyve özelliklerine ait korelasyon katsayısı Çizelge 5'de gösterilmiştir. Buna göre, meyve ağırllğı ile meyve eni $(r=0.84$; $\mathrm{p}<0.01)$, boyu $(\mathrm{r}=0.70 ; \mathrm{p}<0.01)$, yüksekliği $(\mathrm{r}=0.85 ; \mathrm{p}<0.01)$, kabuk kalınlığ1 $(\mathrm{r}=0.59$; $\mathrm{p}<0.05)$ arasında pozitif buna karşılık, iç randıman $1(r=-0.92 ; p<0.01)$ arasında negatif korelasyon bulunmuştur. Meyve ağırlı̆̆ ile meyve boyutları arasındaki kuvvetli ve pozitif yönde olan bu ilişki, badem (Gulsoy ve ark., 2018) ve cevizde de (Acarsoy Bilgin ve ark., 2018) ortaya konmuştur. Meyve iç ağırlığı ile yüksekliği arasında pozitif, meyve eni ile negatif korelasyon gözlenmiştir. Ayrıca meyve eni ile meyve boyu $(r=0.87)$ ve yüksekliği $(r=0.74)$ arasında saptanan kuvvetli ilişki, 307 adet badem genotipinde de Gulsoy ve ark., (2018) tarafindan belirlenmiştir. İç randıman arttıkça meyve ve iç eni, meyve yüksekliğii, kabuk kalınlığı, a renk değeri ve çift iç oranı azalmaktadır. Aynı türde, meyve eni, yüksekliği ve kabuk kalınlığ arasındaki benzer ilişki tespit edilmiştir (Gulsoy ve ark., 2018). Çift iç oranı, iç eni ile pozitif (r $=0.78 ; \mathrm{p}<0.01)$, iç boyu $(\mathrm{r}=-0.80 ; \mathrm{p}<0.01)$ ile negatif ve kuvvetli ilişkiye sahiptir. Ayrıca çift iç oranı arttıkça meyve iç ağırlığında azalış buna karşılık, kabuk kalınlığında artış kaydedilmiştir. Verim ile meyve iç boyu arasında kuvvetli ve negatif korelasyon saptanmıştır $(r=-0.83$; $\mathrm{p}<0.01$ ). Verim ile meyve ağırlığı arasında ilişkinin bulunmaması farklı ceviz genotiplerinde Bayazit (2012) tarafindan da vurgulanmıştır. Ayrıca renk değerleri arasında da pozitif yönde kuvvetli korelasyon bulunmuştur.

\section{Sonuç}

Ege Bölgesi'nde nispeten soğuk iklime sahip Demirci lokasyonunda geç çiçeklenen Ferragnes ve Ferraduel çeșitleri ile yetiștiricilik yapılmaktadır. $\mathrm{Bu}$ çeşitlerle tesis edilen ve organik yetiştirme sisteminin uygulandığ kapama bahçede yürütülen çalışmada; iklim koşulları ve ağacın gelişmesine bağlı olarak, denemenin ilk yılında ince kabuk ve daha az çift iç oran, ikinci yılda ise daha yüksek verim saptanmıştır. Kabuklu bademin eni, Ferraduel çeşidinde daha yüksek iken, iç badem boyu ilk yılda daha uzun olduğu belirlenmiştir. Ayrıca kabuklu meyve boyutları yıllara göre değişim gösterirken, meyve renk değerlerinde farklılık bulunmamıştır. Kabuklu meyve ağırlı̆̆ı, kabuk kalınlığı, kabuklu badem boyutları, iç randımanı ve çift iç oranına ilişkin yapılan değerlendirmede, çeşit $\mathrm{x}$ yıl interaksiyonu istatistiksel açıdan anlamlı bulunmuştur. En yüksek kabuklu meyve ağırlığı, Ferragnes çeşidinde ikinci, Ferraduel çeşidinde ise birinci y1lda ölçülmüsştür. Diğer taraftan, iç randımanı yüksek, ince kabuklu ve çift iç oranı az olan meyveler Ferragnes çeşidinde 2018, Ferraduel çeşidinde ise 2019 yılında elde edilmiștir. Çeşitler arasında istatistiksel olarak farkl1lık görülmemekle birlikte, Ferraduel çeşidinde nispeten verimin daha yüksek olduğu saptanmıştır.

Sonuç olarak, söz konusu meyve özellikleri ve verim bulguları dikkate alındığında, yetiştiriciliğin uygulanabilir olduğu görülmektedir. Özellikle son yıllarda devlet desteği sayesinde bu yetiştiricilik sistemine olan talebin arttığı bilinmektedir. Böylece 
bu meyve türü ve üretim sisteminin yörede yaygınlaştırılabileceği düşünülmektedir.

\section{Teşekkür}

Çalışmanın yürütülmesine olanak sağlayan Sayın Orhan Aztekin'e (Karaoklar Ekolojik Hayat Çiftliği) sonsuz teşekkürler.

\section{KAYNAKÇA}

Acarsoy Bilgin, N., Şen, F., Yağmur, B., Özaktan, H. ve Akbaba, M. 2018. The First Findings to Fruit Characteristics of Nutrient and PGPR Applications on Chandler Walnut Variety . 2nd International Conference on Agriculture, Forest, FoodSciencesand Technologies (ICAFOF) 2-5 April, 2018 Çeşme-İzmir/Turkey. 769-775.

Akçay, M.E. ve Tosun, İ. 2005. Bazı Geç Çiçek Açan Yabancı Badem Çeşitlerinin Yalova Ekolojik Koşullarındaki Gelişme ve Verim Davranışları. Atatürk Üniv. Ziraat Fak. Derg. 36 (1): 1-5.

Açıkgöz, N., Aktaş, M.E., Moghaddam, A. ve Özcan, K. 1993. Tarist PC'ler için İstatistik ve Kantitatif Genetik Paket. Uluslararası Bilgisayar Uygulamalar Semp. 133 s. 19 Ekim 1993. Konya.

Aksoy, U. 2001. Ekolojik Tarım: Genel Bir Bakış.

Türkiye II. Ekolojik Tarım Sempozyumu, 14-16 Kasim, Antalya.

Aslan, R. 2015. Bazı Yabancı Kökenli Badem Çeşitlerinin Şanlıurfa Koşullarında Fenolojik ve Pomolojik Özellikleri. Ordu Üniversitesi Fen Bilimleri Enstitüsü Bahçe Bitkileri Anabilim Dalı, Yüksek Lisans Tezi.
Atalay, C. 2016. Yeni Çevresel Paradigma Ölçeği İle Organik Gıda Tüketicilerinin Çevreye Yönelik Tutumlarının Değerlendirilmesi: Ankara İli Örneği. Yüksek Lisans Tezi, Fen Bilimleri Enstitüsü, Ankara.

Atlı, H.S., Çağlar, S., Kaşka, N., Rastgeldi, U., Soylu, M.K., Aydın, Y., Arpacı, S., Açar, İ., Akgün, A., Bilim, C. ve Ak, B.E. 2008. Yerli ve Yabancı Badem Çeşitlerinin GAP Bölgesi Sulu Koşullarında Gelişme, Meyveye Yatma, Verim ve Bazı Kalite Değerlerinin Belirlenmesi. Antepfistığ Araştırma Enstitüsü Müdürlüğü, Gaziantep. Yayın No:38.

Bayazit, S., 2012. Determination Of Relationships Among Kernel Percentage And Yield Characteristics In Some Turkısh Walnut Genotypes By Correlation And Path Analysis. The Journal of Animal \& Plant Sciences, 22(2): 513-517.

Mcguire, R.G. 1992. Reporting of ObjectiveColor Measurements. Hortscience 27: 1254-1255.

Dokuzoğuz, M. ve Gülcan, R. 1973. Ege Bölgesi bademlerinin seleksiyon yoluyla 1slahı ve seçilmiş tiplerin adaptasyonu üzerine araştırmalar. TÜBİTAK, No:22.

Ersun, N. ve Arslan, K. 2011. Turizmde destinasyon seçimini etkileyen temel unsurlar ve pazarlama stratejileri. Marmara Üniversitesi İ.İ.B.F. Dergisi, 31(2): 229248.

Gök, S.A. 2008. Genişleyen Avrupa Birliği pazarında Türkiye'nin organik tarım ürünleri ticareti açısından değerlendirilmesi. Tarım ve Köy İşleri Bakanlığı AB Uzmanlık Tezi, Ankara. 
Gülsoy, E. ve Balta, F. 2014. Aydın ili Yenipazar, Bozdoğan ve Karacasu ilçeleri badem (Prunus amygdalus Batch) seleksiyonu: pomolojik özellikler. Akademik Ziraat Dergisi 3(2): 61-68.

Gulsoy, E., Simsek, M., Kara, M.K. ve Balta F. 2018. Assessment of relationship between fruit characteristics of almond selections from Aydin regon using canonical correlation analysis method. Fresenis Environmental Bulletin. 27 (7): 4668 4673.

Karaat, F.E. 2019. Organic vs Conventional Almond: Market Quality, Fatty Acid Composition and Volatile Aroma Compounds. Applied Ecology and Environmental Research 17(4): 77837793. http://dx.doi.org/10.15666/ aeer/1704 77837793

Küden, B.A., Küden, A., Bayazit, S., Çömlekçioğlu, S., İmrak, B. ve Rehber Dikkaya, Y. 2014. Badem Yetiştiriciliği. TAGEP Proje No:5.2.3.1.

Oğuz, H.İ., Erdoğan Bayram, S. ve Eroğul, D. 2011. Gap Üst Bölgesinde kurak koşullarda yetiştirilen standart badem (Prunus amygdalus Batsch.) çeşitlerinde biyokimyasal ve yağ asitleri kompozisyonlarının belirlenmesi üzerine bir araştırma. GAP VI. Tarım Kongresi, 09-12 May1s.

Özyazıc1, G., Özdemir, O., Özyazıcı, M.A. ve Üstün, G.Y. 2010. Bazı organik materyallerin ve toprak düzenleyicilerin organik fındık yetiştiriciliğinde verim ve toprak özellikleri üzerine etkileri. Türkiye 4. Organik Tarım Sempozyumu. 28
Haziran-1 Temmuz. Erzurum. 368-372.

Parlakçı, H. 2008. Yabancı Kökenli Değişik Badem Çeşitlerinin Bazı Pomolojik ve Kimyasal Özellikleri ile Bitki Besin Maddesi Kapsamlarının Belirlenmesi. Yüksek Lisans Tezi. Harran Üniversitesi, Şanlıurfa.

Simsek, M. 2016. Chemical, mineral and fatty acid compositions of various types of walnut (Juglans regia L.) in Turkey. Bulgarian Chemical Communication, 48: 66-70.

Turan, A., Ruşen, M., Islam, A., Kurt, H., Ak, K., Sezer, A., Sarığlu, M., Kalyoncu, I.H. ve Kalkışım, Ö. 2010. Giresun koşullarında organik fındık üretim imkanlarının araştırılması. Türkiye 4. Organik Tarım Sempozyumu. 28 Haziran-1 Temmuz. Erzurum. 123-129.

Yercan, M. ve Özden, F. 2015. Manisa İli Organik Tarım ve Hayvancılık Stratejisi ve Eylem Planı. TC Gıda Tarım ve Hayvancılık Bakanlığı Manisa İl Müdürlüğü, teknik rapor.

Yıldız, E. ve Erol Perdahcı, Ç. 2019. Uşak Ekolojik Koşullarında Bazı Badem Çeşitlerinin Adaptasyonu. Erciyes Tarım ve Hayvan Bilimleri Dergisi, 2 (1): 11-19. 